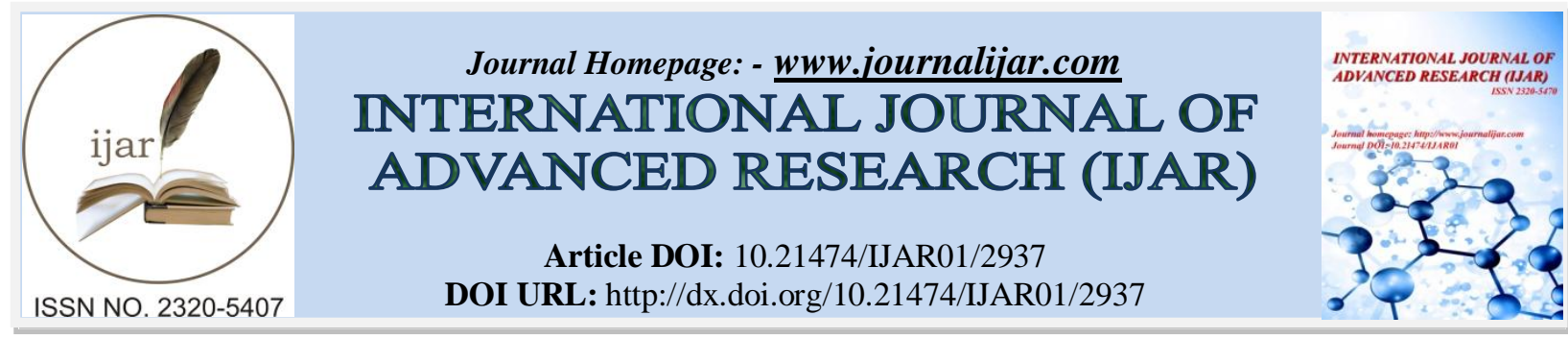

RESEARCH ARTICLE

\title{
COMPLETE NUCLEOTIDE SEQUENCE OF A MONOPARTITE TOMATO LEAF CURL NEW DELHI VIRUS AND BETASATELLITE DNA ASSOCIATED WITH LEAF CURL DISEASE OF TOMATO IN INDIA.
}

\author{
Abhinav Kumar ${ }^{1,2}$, Taruna Gupta ${ }^{3}$, Seema Singh $^{4}$ and Neera B. Sarin ${ }^{1}$. \\ 1. School of Life Sciences, Jawaharlal Nehru University, New Mahrauli Road, New Delhi-110067, India \\ 2. Dept. of Biotechnology, School of Sciences, Noida International University, GB Nagar, Greater Noida, Uttar \\ Pradesh, India \\ 3. Centre for research studies, Noida International University, GB Nagar, Greater Noida, Uttar Pradesh, India \\ 4. University of Kashmir Hazratbal, Srinagar, Jammu and Kashmir- 190006, India
}

\section{Manuscript Info}

Manuscript History

Received: 25 November 2016

Final Accepted: 27 December 2016

Published: January 2017

Key words:-

Begomovirus, Tomato leaf curl virus,

Phylogenetic analysis

\begin{abstract}
A begomovirus was isolated from tomato plants showing typical leaf curl and stunting symptoms in tomato fields near the Delhi, India. Viral genomic components were enriched by rolling-circle amplification; PCR amplified and were cloned and sequenced. The genome organization of this virus was found to be similar to those of Old World monopartite begomovirus, with DNA-A and a betasatellite component. The alphasatellite or DNA-B component was not detected. The complete nucleotide sequence of DNA-A shared highest similarity with Tomato leaf curl New Delhi (ToLCNDV) virus while betasatellite DNA showed similarity with betasatellite DNA reported from infected leaves of Tomato, Sunflower and Potato. The data present here strongly support the association of a monopartite ToLCNDV and betasatellite DNA with the leaf curl disease of tomato.
\end{abstract}

Copy Right, IJAR, 2016,. All rights reserved.

\section{Introduction:-}

Tomato leaf curl disease (ToLCuD), caused by Tomato leaf curl virus (ToLCV) is one of the most devastating causal agents for the loss of tomato (Solanum lycopersicum) crop which has spread substantially and covers new areas in tropical and subtropical continents every year. This virus belongs to the genus Begomovirus, a whitefly (Bemisia tabaci) transmitted virus which comes under family Geminiviridae. Begomoviruses infect dicotyledonous plants and have either a bipartite genome with two single-stranded (ss) DNA components designated as DNA A and DNA B, each one about $2.7 \mathrm{~kb}$ in size, or a monopartite genome with one ssDNA component analogous to DNA-A (Briddon et al., 2012; Kumar et al., 2011). Begomovirus genes required for virus replication and encapsidation by coat protein are encoded by DNA-A component and those for virus movement (both intra and intercellular) by DNA-B. In monopartite begomoviruses, genes for replication, encapsidation and movement are present in a single component (DNA-A) (Murthi et al., 2007).

In Indian subcontinent, ToLCV is a major problem in tomato-growing regions and several reports on new strains have been documented from New Delhi, Lucknow, Bangalore, Varanasi, Mirzapur, Vadodara, and Western Uttar Pradesh (Chakraborty et al., 2003). In recent years, another component designated as betasatellite (single stranded DNA) has been found to be associated with Old World monopartite begomoviruses. This small, circular DNA has 
size approximately half $(\sim 1.3 \mathrm{~kb})$ to that of DNA-A, and is capable of inducing symptom in plants. It is dependent on DNA-A for replication, encapsidation and transmission (Briddon et al., 2001; Briddon et al., 2008). In addition to betasatellites, monopartite viruses are sometimes found to be associated with another type of satellite designated as alphasatellite, which encodes one replication initiation protein. The role of these alphasatellites in pathogenesis is not yet clears (Briddon et al., 2008).

Indian ToLCV isolates are mostly monopartite (DNA-A) in nature with few isolates possessing bipartite (DNA-A and DNA-B) genome organization such as tomato leaf curl New Delhi virus (ToLCNDV) and tomato leaf curl Palampur virus (ToLCPalV) (Briddon et al., 2008). Here we report the presence of monopartite ToLCNDV and betasatellite DNA associated with the leaf curl disease of Tomato from New Delhi region.

\section{Materials and Methods:-}

Virus source and DNA isolation:-

During the month of May-June, 2012, leaves were collected from tomato plants showing typical leaf curl, vein thickening and stunting symptoms in the fields near Delhi (Latitude: 28.61and Longitude: 77.20), India. Total DNA was isolated (Dellaporta et al., 1983) and viral genomic components were enriched via rolling-circle amplification, and PCR amplified using specific primers for full-length (DNA-A) and betasatellite DNA (Briddon et al. 2001; Kumar et al. 2011).

\section{Cloning and sequencing:-}

PCR amplified product was run on agarose gel and visualized in UV illumination. DNA fragments representing CP gene and betasatellite DNA were excised from the gel and purified using HiPura gel extraction kit (Hi Media Pvt.Ltd. India) following manufacturers instruction. The DNA fragments were cloned into pDrive vector (QIAGEN, Germany). The recombinant plasmid was then transformed into Escherichia coli DH5 $\alpha$ cells and positive clones containing desired DNA fragments were sequenced using automated sequencer.

\section{Sequence analysis:-}

Nucleotide sequences of full-length genome of ToLCuV and betasatellite DNA under study were aligned with those of other begomovirus sequences from Gen Bank using CLUSTAL W (Tamura et al., 2013) alignment program. Following multiple sequence alignments, phylogenetic analysis was done using MEGA software version 6.0 (Tamura et al., 2013). Default parameters used were character- based algorithm (Maximum Parsimony), and distance-based algorithms (Minimum Evolution and Neighbour-Joining). A consensus dendrogram was generated using bootstrap value of 1000 replicates for these algorithms. The expasy proteomic server tool was used to translate set of protein encoding genes.

\section{Results and Discussion:- Phylogenetic analysis:-}

The sequences obtained were combined using several sequences available in the GenBank. The complete nucleotide sequence data of DNA-A of the begomovirus consisted of 2,730 nucleotide (Acc. no. JX460805), which shared highest (90\%-94\%) nucleotide identity with DNA-A component of several isolates of ToLCNDV (FN435310, HM159454, U15015, JN129254, HM159454), followed by <90\% similarity with Squash leaf curl china virus [Pum:IARI], Bhendi yellow vein Haryana virus, Squash leaf curl China virus [Pum: Lucknow] (JN587811, FJ561298, DQ026296). The genome organization of this virus was found to be similar to those of Old World monopartite begomovirus, with DNA A and a betasatellite component. However, an attempt to amplify alphasatellite or DNA B component was unsuccessful.

The betasatellite DNA consisted of 1359 nt and was assigned accession number JX679002. The betasatellite DNA shared maximum identity (90-97\%) with betasatellite DNA of Tomato leaf curl virus (AY438557), Sunflower leaf curl virus (JX678964), Potato apical leaf curl disease (EF043234), Papaya leaf curl virus (DQ118862, JX050199) etc. However it shared less sequence similarity $(<70 \%)$ with betasatellite DNA from Cotton leaf curl Multan virus or Cotton leaf curl Burewala virus. The sequence of betasatellite DNA shows the typical arrangement of betasatellites, (1) a single open reading frame (ORFs) in the complementary sense (known as $\beta \mathrm{Cl}$; coordinates 557-201); (2) a region of sequence rich in adenine (coordinates 706-986); and (3) a sequence motif highly conserved between all betasatellite DNA satellites, known as the satellite conserved region (SCR; coordinates 1260-14). The ORF $\beta C 1$ is predicted to encode a 119-amino-acid protein. 
The phylogenetic analysis of complete sequence of ToLCNDV under study showed its clustering with ToLCNDV has been reported from Pakistan. The betasatellite DNA clustered with betasatellite reported mostly from nonSolanaceae family. This kind of incidence may occur due to high inoculum pressure or high adaptation capability of the host. This report of monopartite ToLCNDV associated with betasatellite DNA may give some insight into the types of Tomato leaf curl virus infecting tomato crops in north India. There were earlier reports of bipartite ToLCV associated with leaf curl disease of tomato in North India, and monopartite ToLCV in South India (Chowda et al., 2005), but due to more and more sample analysis across the country this opinion is no longer valid, as both types are found from infected tomato plants in all parts of the country (Tiwari et al., 2013). However, monopartite Tomato leaf curl Gujarat virus (ToLCGuV) is now a dominant monopartite begomovirus with betasatellite associated with tomato leaf curl disease in India (Jyothsna et al., 2013).

The search on the available literature and sequences present in NCBI suggests only bipartite ToLCNDV without betasatellite DNA is associated with leaf curl disease of tomato. The report of a monopartite ToLCNDV naturally infecting tomato will add to the variability of ToLCV. Additionally, the data present here strongly supports the association of a monopartite ToLCNDV and non-solanaceous betasatellite with leaf curl disease of tomato in North India.

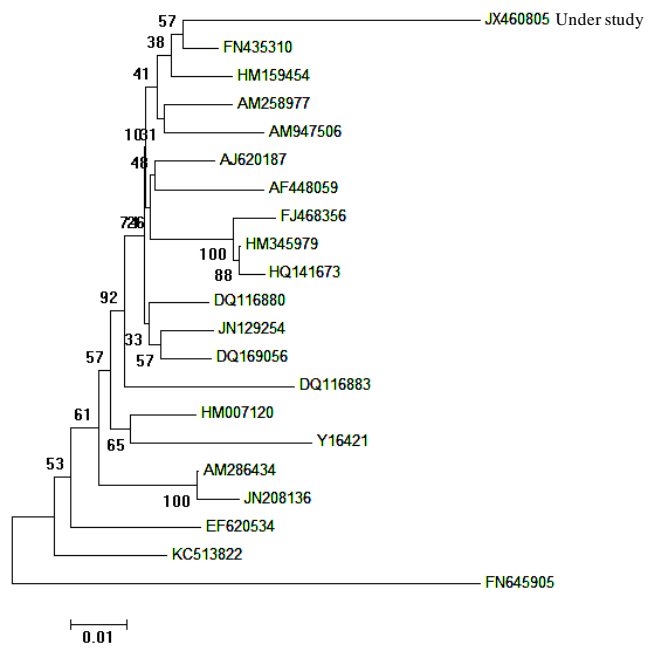

Fig. 1:- Phylogenetic analysis of DNA-A molecules of this study with other DNA-A molecules of different ToLCV. The optimal tree with the sum of branch length $=0.44812555$ is shown. The tree was generated using the NeighborJoining method in MEGA 6.0 (software). The percentage of replicate trees in which the associated taxa clustered together in the bootstrap test (500 replicates) is shown next to the branches. The evolutionary distances were computed using the Maximum Composite Likelihood method and are in the units of the number of base substitutions per site.

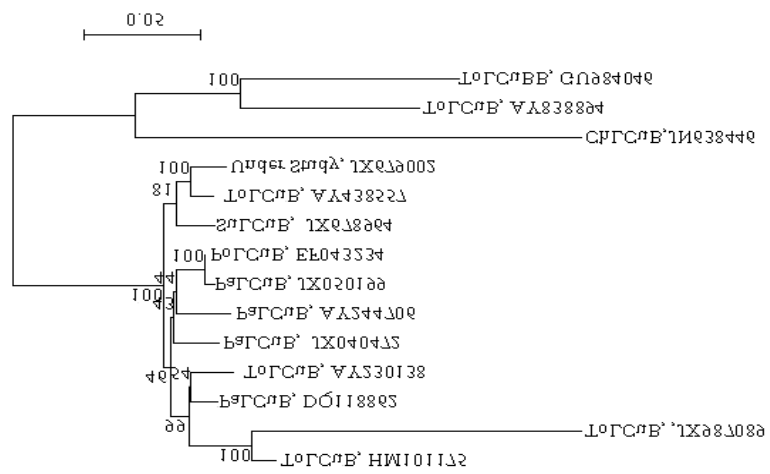

Fig. 2:- Dendrogram showing a relationship of betasatellite (this study) with other betasatellite associated with begomoviruses. The optimal tree with the sum of branch length $=0.86863634$ is shown. The percentage of replicate trees in which the associated taxa clustered together in the bootstrap test (500 replicates) is shown next to the 
branches. The evolutionary distances were computed using the Maximum Composite Likelihood method, and the evolutionary history was inferred using Neighbor-Joining method in MEGA 6.0 software.

\section{Acknowledgement(s):-}

First author is thankful to UGC for providing Dr. D.S. Kothari Post Doctoral Fellowship.

\section{References:-}

1. Briddon, R.W., Ghabrial, S., Lin, N.S., Palukaitis, P., Scholthof, K.B.G., Vetten, H.J. (2012): Virus taxonomy: classification and nomenclature of viruses. Ninth Report of the International Committee on Taxonomy of Viruses. In: King AMQ, Adams MJ, Carstens EB, Lefkowitz EJ (eds) Satellites and other virus dependent nucleic acids. Elsevier, San Diego., pp 1211-1219.

2. Briddon, R.W., Mansoor, S., Bedford, I.D., Pinner, M.S., Saunders, K., Stanley, J., Zafar, Y., Malik, K.A., Markham, P.G., (2001): Identification of DNA components required for induction of cotton leaf curl disease. Virology., 285: 234-243.

3. Briddon, R.W., Brown. J.K., Moriones. E., Stanley, J., Zerbini, M., Zhou, X., Fauquet, C.M., (2008): Recommendations for the classification and nomenclature of the DNA-b DNA- $\beta$ satellites of begomoviruses. Arch. Virol., 153: 763-781.

4. Chakraborty, S., Pandey, P.K., Banerjee, M.K., Kalloo, G., Fauquet, C.M .,(2003): Tomato leaf curl Gujarat virus, a new begomovirus species causing a severe leaf curl disease of tomato in Varanasi, India. Phytopathology., 93(12): 1485-1495.

5. Chowda, Reddy, R.V., Colvin, J., Muniyappa, V., Seal, S., (2005): Diversity and distribution of begomoviruses infecting tomato in India. Arch. Virol., 150: 845-867.

6. Dellaporta, S.L., Wood, J. and Hicks, J.B., (1983): A plant DNA minipreparation: Version III. Plant Molecular Biology Reporter., 1: 19-21.

7. Jyothsna, P., Rawat, R., Malathi, V.G., (2013): Predominance of tomato leaf curl Gujarat virus as a monopartite begomovirus: association with tomato yellow leaf curl Thailand betasatellite. Arch. Virol., 158: 217-224.

8. Kumar, A., Kumar, J., Khan , J. A., (2010): Sequence characterization of cotton leaf curl virus from Rajasthan. Phylogenetic relationship with other members of geminivirus and detection of recombination. Virus. Genes., 40: 282-289.

9. Kumar, A., Snehi, S.K., Raj, S.K., Kumar, J, Khan, J.A., (2011): Association of Cotton leaf curl Burewala virus and an alphasatellite with cotton leaf curl disease in India. New Disease. Reports., 24: 18.

10. Murthi, M.N., Rekha, A.R., Mirza, S.H., Alam, S.N. and Colvin, J., (2007): A novel begomovirus with distinct genomic and phenotypic features infects tomato in Bangladesh. Virus. Genes., 34: 373-385.

11. Tamura, K., Stecher G, Peterson D, Filipski A, Kumar, S., (2013): Molecular Evolutionary Genetics Analysis (MEGA) Software Version 6.0. Mol.Biol.Evol. 30: 2725-2729.

12. Thompson, J.D., Higgins, D.G., Gibson, T.J., (1994): CLUSTAL W: Improving the sensitivity of progressive multiple sequence alignment through sequence weighting, position-specific gap penalties and weight matrix choice. Nucleic Acid Res. 22: 4673-4680

13. Tiwari, N., Singh, V.B., Sharma, P.K., Malathi, V.G., (2013): Tomato leaf curl Joydebpur virus: a monopartite begomovirus causing severe leaf curl in tomato in West Bengal. Arch. Virol., 158: 1-10. 